\title{
A IMAGEM DO HOMEM NA ANTROPOLOGIA DE KANT ${ }^{1}$
}

\section{Arnold von Buggenhagen}

Professor da Faculdade de Fiosofia, Ciências e Letras de São José do Rio Pardo

A Antropologia de Kant não é ciência em si fechada, mas estriba em peculiares pressuposições: em teses relativas à essência humana, teses apresentadas pela filosofia como resultado de seus esforços. Sentidn e ethos, estrutura global e metódica da ciência antropológica são apenas plena ruente compreensíveis se tomamos em consideração o fundo ideológico da filosofia que lhes serve de base.

$\mathrm{Na}$ secção da Antropologia, subordinada ao título "O caráter da espécie", trata-se, de modo peculiar, da essência do homem e de seu destino, para sumàriamente se esboçar uma imagem filosófica do homem (pp. 523$537)^{2}$.

O método de caracterização empregado por Kant é duplo. Um caminho para tirar a limpo algo súbre a essência humana, é a aplicação do pensamento classificatório. A espécie é "compreendida sob um conceito juntamente com outras espécies de nós conhecidas, mas o que entre si as distingue como propriedade (proprietas) é apontado e usado como fundamento de distinção" (p. 523). À medida que se avança na investigação, sensivel se torna a falha do método classificatório. A característica, tomada como critério dêste método, salienta uma peculiaridade da essência humana, tal como esta aparece, não pode todavia por sua natureza ir ao ponto de determinar os caracteres, que ao homem são atribuídos. O mecanismo elucidativo que explicita o precedente pensamento classificatório e completa, sob êste respeito, o retrato humano, é descrito mediante fórmulas, como "intenção, sabedoria da natureza", "providència" e outras semelhantes.

Que a aplicação do método classificatório, assim provado, ao objeto da natureza vegetal e animal signifique uma delimitação capaz de ser fixada em presença da maneira peculiar de ser da essência humana, é mais que manifesto, se no anterior conceito da discriminação da característica humana fôr incluída a "essência racional em geral". "O supremo conceito específico (do homem) pode ser o de uma essência racional terrestre, no qual caso será impossivel apontar qualquer caráter da mesma, pois que não possuímos nenhum conhecimento de essências racionais não-terrestres, que nos faculte indicar sua peculiaridade e, por êsse meio, caracterizar em geral as essências terrestres entre as racionais" (p. 523). Kant cede acidentalmente, e precisamente em meio de sua pesquisa, à tentação de es- 
hoçar, mediante ficticia manobra mental, um estado angélico, para dêsse modo chegar a alguma conclusão sôbre a fisiognômica do gênero humano (por exemplo, a questão de discutir se a espécie humana como species de sêres racionais terrestres em comparação com uma outra espécie existente noutros planetas é boa ou má em sua "raça", mas é óbvio que idéias de tal proveniência, longe de poderem reclamar para si a autoridade de uma declaração rigorosamente fundamentada, são antes a manifestação de um gracejo chocarreiro, cujas argumentações cada qual pode avaliar como muito bem the pareça (valeant quantum possunt)).

Ao invés, excelente é o método classificatório, para indicar ao homem o pôsto que lhe compete no sistema da natureza vivente. Perante o ser da natureza vivente ergue-se o animal, dotado da capacidade de razão, ao qual está subordinado um específico domínio de ação, mas que nem por isso deix de permanecer em sua categoria de animal, isto é, o animal dotado de inclinação para não escutar os mandamentos da razão, e capaz de dar ouvidos passivamente à felicidade, aos atrativos da comodidade e da boa vida, como as molas propulsoras de seu comportamento.

Três são as notas distintivas que assinalam o homem em face da natureza privada de razão. ( homem é dotado de uma disposição natural técnica, pragmática e moral. A disposição técnica permite-lhe servir-se da razão para operações mecânicas ligadas com a consciência no mundo das coisas. Fisicamente mostra-se esta disposição como animal racional na forma e organização da mão, a qual, não sendo feita para determinada espécie de manuseio das coisas, é ordenada miversalmente, e sem restriçóes, a desempenhar-se de tôdas as funções possíveis. A disposição pragmática hakilita-o a utilizar-se hàbilmente dos homens seus semelhantes para seus fins. Graças à evolução das relações sociais, é êle apto para seguir a seu modo sua tendência natural, de sorte que no convívio social se desprenda da rudeza da mera violência própria e se converta em ser civilizado (embora não ainda moral), isto é, em ser destinado a viver em harmonia com outros. Sendo assim, mostra-se capaz de receber educação (tanto no sentido de instrução, como no de disciplina). A disposição moral, por outras palavras, o ser ingênitamente prendado de potências racionais práticas (que se manifestam na consciência da liberdade do livre arbitrio) constitui, tanto como as disposições técnica e pragmática, uma particularidade que distingue o homem do animal; é fato verificado, que se revela na consciência de sentir moralmente, mesmo no meio das mais obscuras representaçóes, que ao homem ou pelo homem sobrevém a outros o bem ou o mal.

Estas três disposições encontram o estôfo essencial de suas manifestações em três domínios: 1) mercê das mencionadas disposições ingênitas mantém-se o homem e sua espécie; 2) exerce-se, instrui-se e educa-se para a comunidade humana; e 3 ) rege-se como um todo sistemático (ordenado segundo princípios racionais) pertencente à sociedade. Materialmente, pode 
êle simultâneamente ter algo de comum com o reino animal, todavia a maneira como o estôfo bruto da comunidade é determinado por uma disposição técnica, pragmática e moral, participa do caráter peculiar que o contrapõe às estruturas sociais da atividade animal.

Quanto à subseqüente caracterização do homem de acôrdo com pontos de vista classificatórios, é ela ultrapassada por Kant, quando êste reclama também, para a determinação do homem, a racionabilidade que o habilite a poder ser animal racional, já que o homem deve desenvolver-se no sentido de vir a ser animal racional. Esta caracterização da espécie humana não se deve eximir à comparação de dados empíricos entre a natureza terrestre-humana e a terrestre-sub-humana; mas guia-se por um mecanismo explicativo de outra espécie, a saber, um mecanismo explicativo cujo conteúdo se expressa mediante fórmulas como "vontade" ou "intenção da natureza", "providência". etc., como atrás fica dito.

O raciocínio, que leva a atribuir ao homem além da racionabilidade (aptidão para a razão) a destinação para ser racional, é puramente especulativo nos possíveis resultados: não pode recorrer a dados como o método classificatório, cujas determinações se manifestam em dados do sistema natural humano e não-humano, mas carece de tal garantia. Desconhece todavia a capacidade operativa dêste método quem suponha que, pelo fato de ser especulativo, êle seja inteiramente livre de peias e abra caminho ao livre arbítrio subjetivo para dar lugar a qualquer determinação no ser humano. O processo especulativo pode estar ligado a princípios que o consolidem, como, por exemplo, a idéia de o destino de cada ser vivente já estar prèviamente dado em sua disposição ingênita. Justamente tal principio é proclamado por Kant na proposição: a natureza quer "que cada criatura alcance sua destinação, desenvolvendo tôdas as disposições natulais em conformidade com o fim da mesma, de sorte que, senão cada individuo, ao menos a espécie cumpra a intenção da mesma" (p. 532). E lògicamente êste mesmo princípio é também obrigatório, quando se trata de determinar o fim metafísico da espécic humana.

Como produto de uma especulação teòricamente fundamentada sôbre a essência do homem, é aceitável a proposição: deve êle desenvolver-se a partir de um animal capaz de razáo (racionável) até ser animal racional. Podem todavia as duas disposições do homem contrárias: sua tendência animal e sua capacidade de razão, ser consideradas como provas de que a natureza quis ter o domínio do uso da razão sôbre a natureza animal.

Vão tôdas orientadas nesta direção as considerações de Kant sôbre a essência do homem. O homem não é primeiramente um ser, um animal dotado de razão, mas, como animal dotado de razão, é destinado a alguma coisa. E, em conformidade com isto, escreve: "O homem tem um caráter que êle se cria a si mesmo, enquanto dispóe do poder de se aperfeiçoar de acôrdo com seus fins, por si mesmo aceites, mediante o qual, como anị 
mal dotado de capacidade de razão que é (animal rationabile), por si mesmo se pode tornar animal racional (animal rationale)" (p. 523). Por outras palavras: "O homem é determinado por sua razão para viver com outros homens em sociedade, e nesta se cultivar, se civilizar e se moralizar pela arte e pela ciência, por maior que seja sua tendência animal para se abandonar passivamente aos atrativos da comodidade e da boa vida, que êle denomina felicidade; deve antes mostrar-se ativo, lutar contra os obstáculos decorrentes da rudeza de sua natureza, a fim de se mostrar digno da humanidade" (p. 523).

Entretanto, no texto das definições de Kant permanece implícito ou não totalmente claro o exato conteúdo real das considerações especulativas sôbre a essência do homem.

A importância das declarações, contidas nas proposições acima mencionadas, torna-se explícita e visivel, se tirarmos a limpo a peculiaridade do ser humano, mediante o confronto entre a essência do homem e a das restantes criaturas naturais por um lado e, por outro lado, entre a essência do homem e uma essência fictícia.

1) O mundo animal é dotado pela natureza com os automatismos de seus instintos; a natureza mantém êste domínio a cuidado das leis que a regem e com isso garante-lhe a finalidade, de maneira que não só a espécie como um todo, mas também cada indivíduo da espécie cumpra o destino que the é fixado. O mundo animal, por sua natureza, de maneira nenhuma pode cooperar para que ela cumpra seu destino.

Como conseqüência da atribuição de racionabilidade ao ser do homem, a natureza retira sua mão protetora dêste. Em lugar do automatismo dos instintos inatos surge a faculdade de aperfeiçoamento, baseada na própria espontaneidade e liberdade. A natureza dotou de tal sorte o homem que êle é capaz de tudo executar para alcançar o fim de seu destino, intentado pela mesma natureza: mas a natureza não o determinou univocamente, a ponto da êle fazer tudo quanto está em suas possibilidades. A essência da espontaneidade da liberdade inata no homem como ser racional é tal que èle pode por si fazer tudo para, e também tudo contra a realização da exigência obrigatória da natureza.

2) O homem não é definido como animal racional (animal rationale), mas como animal capaz de razão (animal rationabile). Importa discriminar rigorosamente ambos os conceitos. A essência racional seria lógicamente sempre também uma essência racionável. Mas se invertermos a proposição, chegamos a uma falsa conclusão: uma essência racionável não deve necessàriamente, mas pode, sob determinadas condições, tornar-se racional. Quer isto dizer que a realização do próprio ser é executada, na essência racionável, à base de sua liberdade (livre arbítrio na decisão da possibilidade de escolha), mas não é determinada automàticamente no sensido da razão. 
Se o homem fôsse uma essência inteiramente racional (animal rationale) e não apenas uma essência racionável (animal rationabile), sua organização constituiria um grau supremo na esfera ontológica da natureza, desde que a riqueza de caracteres fôsse o critério de superioridade do ser, mas nesse caso a sobrevivência da razão não significaria para êle nenhuma situação especial fundamental. Do mesmo modo que a natureza guia os animais pelo mecanismo dos instintos, guiaria, nessa hipótese, o homem pelo automatismo da razão. Na qualidade de essência racional por constituição, o homem não poderia proceder senão em conformidade com a razão e ficaria privado da liberdade de decidir contra a razão. Mas êle não e constituído de maneira que o mecanismo da razão opere nele como um automatismo. O específico do ser humano é a capacidade de razão (a racionabilidade): há nele um mecanismo de liberdade, tal que, mercê do próprio livre arbitrio (e não por causa de leis que lhe sejam inerentes), êle possa ser, mas não deva ser aquilo que lhe é determinado.

Mostra a elucidação das definições a seguir aduzidas por Kant, que ilustram a essência do homem em confronto com o ser animal e com o ser simplesmente racional, que, como momento principal na especulação da concepçáo do ser humano, não tanto é de importância sua determinação, quanto, ao invés, a liberdade de opção dada com a racionabilidade: o ser específico do homem é um ser em estado de liberação, um ser que se manifesta no estádio preliminar à realização de um ser bom ou mau na forma de realização empírica. Mediante a atribuição da liberdade de opção, a natureza levou a cabo a obra de arte, que consiste em o homem ter a responsabilidade de si próprio, e entregou-lhe nas máos a tarefa de decidir por si, se se deve conformar com ela, natureza, e com sua finalidade, ou cair no nada, desviando-se de sua vocação. Portanto a essência do homem reside na espontaneidade da opção, cabendo-lhe decidir, também por motivo de sua origem, por aquilo que a natureza dêle exige.

Seu ser neste mundo é o ser de uma liberdade, mediante a qual êle decide seu destino no sentido de pleno cumprimento de sua determinação ou contra esta.

Temos aqui um ponto, no qual se torna clara, em Kant, a união entre filosofia e antropologia.

A importância das considerações precedentes, cuja fôrça probativa por certo não basta para tirar à teoria o caráter de empreendimento puramente especulativo, é suficiente para que o Autor lhe atribua uma certeza moral, isto é, para que compreenda os processos mentais antropológicos sôbre a essência do homem não já como pura teoria, mas como verdade pràticamente obrigatória para o individuo. Se a teoria do homem como animal dotado de razão, determinado a tornar-se animal racional mediante o uso arbitrário de sua liberdade, goza de certeza moral, nesse caso é manifesta a necessidade de uma conversão do pensamento, de teo- 
rético em prático, para cada individuo da espécie humana: eu, como individuo, encontro-me não mais na posição de quem teoriza livremente, mas sou, em meu pensar, um homem sotoposto às condições concretas, que irradiam do pensamento universal para a essência do homem. Certeza moral de uma teoria significa o mesmo que o dever de operar para o fim apontado pela teoria, ou, em têrmos concretos: "no caminho que leva ao melhor" (isto é, na possibilidade do reto uso da liberdade da vontade), "não desesperar, mas com prudência orientadora moralmente promover a aproximação a êste fim (na medida em que fôr possivel a cada qual)" (p. 532).

As experiências da certeza moral da especulação sôbre a essência do homem introduzem a idéia da "Antropologia sob o ponto de vista pragmático". Pois a "Antropologia sob o ponto de vista pragmático" não é mais do que a ciência que sentiu o apêlo da metafísica e, fazendo uso da universal capacidadę de razão, compreende tôdas as disposições para guiar o homem sistemàticamente, em geral e em particular, no reto uso de sua razão, a fim de realizar a intenção da natureza na consecução do destino rremeditado.

\section{NOTAS}

1) O presente artigo, que talvez mais tarde deva ser completado nesta mesma revista por um segundo trabalho intitulado "A forma científica da Antropologia de Kant", propõe-se apenas servir de pequena contribuição para a história da Antropologia.

De duas espécies são os motivos que nos levaram a expor o pensamento de Kant.

O célebre, mas ger lmente pouco conhecido escrito de Kant, não tem, na realidade, importâiıı maior na evolução do pensamento antropológico. Não contém nenhuma idéia revolucionária, capaz de ser tomada para ponto de partida da moderna Antropologia enquanto ciência positiva. Todavia, como escrito histórico, continua sendo notável não apenas como depoimento da expressão e formação mental da época, mas também como testemunho da intensidade de elaboração e da elevação do trabalho científico. A obra faz parte de um pensamento amplo, compreensivo, é obra curiosa quanto à clareza de método e riqueza de matéria apresentada, para não falar da profundidade do conteúdo, por vêzes alcançada na maneira de apreender o caráter humano. A Antropologia não é o fruto de interêsse acessório de momento; ao longo de trinta anos se dedicou Kant a elaborar esta ciência, cuja temática lhe dava assunto bastante de exposição num curso universjtário público, durante um semestre em cada ano. A Antropologia não é, pois, apenas um testemunho representativo do pensamento da época, como também uma prova da mentalidade da mesma época; pelo menos é verossímil pressupor isto, dado que possivelmente muitas das influências anônimas sôbre a maneira de sentir dos coetâneos devem ter surgido de exposições que regularmente se repetiam. Tudo isto são qualidades que justificam um olhar retrospectivo, apesar de o escrito de Kant não ostentar nenhuma significação revolucionária num ramo restrito do saber. 
O contraste, relativamente grande, entre a Antropologia de Kant e a hodierna Antropologia como ciência positiva, pode todavia conferir à recordação histórica um caráter de atualidade, pois que o confronto de duas posiçôes científicas, rie, tendo o mesmo objeto comum, aprestentam diferenças fundamenta.s na intenção epistemológica e nos elementos de conhecimento, pode muito bem aguçar a consciência do estado em que se encontra a moderna Antropologia.

2) As citações referem-se ao texto da "Anthropologie in pragmatischer Hinsicht" da edição de Inselverlag: Immanuel Kant's sämtliche Werke in 6 Bänden, 1. Volume, Escritos vários, pp. 289-537 (sem data).

(Tradução de Antônio Pinto de Carvalho) 